\title{
An attempt to distinguish between the direct and indirect effects, in the laying domestic fowl, of added dietary copper sulphate
}

\author{
BY MARY H. STEVENSON AND N. JACKSON \\ Agricultural and Food Chemistry Research Division, Department of Agriculture \\ for Northern Ireland, and the Queen's University of Belfast, Newforge Lane, \\ Belfast BT9 5PX, Northern Ireland
}

\section{(Receivea' 16 October 1980 - Accepted 12 January 1981)}

\begin{abstract}
1. An experiment is reported in which the effects of giving copper sulphate-supplemented diets and control unsupplemented pair-fed diets tc laying hens were compared.

2. The level of food intake significantly adversely affected mean body-weight, egg number, egg weight, liver, kidney, oviduct and ovary weights. Gizzard weight/kg body-weight was significantly increased both with decreasing levels of food intake and increased $\mathrm{CuSO}_{4}$ supplementation.

3. There was evidence of a depressing effect of $\mathrm{CuSO}_{4}$ per se on egg production and possibly on oviduct and ovary weight.

4. Liver lipid concentration was significantly decreased with decreasing levels of food intake and the results also suggest a depressing effect of $\mathrm{CuSO}_{4}$.

5. The $\mathrm{Cu}$ concentrations and total contents in liver and kidneys were significantly increased by dietary added $\mathrm{CuSO}_{4}$. Liver and kidney $\mathrm{Zn}$ and. Fe concentrations were increased with decreasing levels of food intake rather than by $\mathrm{CuSO}_{4}$ addition.
\end{abstract}

The effects on laying hens of giving high and moderately high levels of dietary copper sulphate, $\mathrm{CuSO}_{4} .5 \mathrm{H}_{2} \mathrm{O}$ have been studied by Thomas et al. (1974), Griminger (1977), Jackson et al. (1979), Stevenson \& Jackson $(1980 a, b)$ and Jackson \& Stevenson (1981).

A consistent finding in all these experiments has been the marked reduction in food intake and egg production which accompanies the consumption of diets containing high levels of added dietary $\mathrm{CuSO}_{4} \cdot 5 \mathrm{H}_{2} \mathrm{O}$. Also the water intake has been shown to decrease at levels of dietary $\mathrm{CuSO}_{4}$ providing more than $500 \mathrm{mg}$ copper $/ \mathrm{kg}$ (Jackson, 1977; Jackson et al. 1979). Associated with these effects decreases in liver lipid content and oviduct size and an increase in gizzard weight have been observed. Liver $\mathrm{Cu}$ and iron concentrations were elevated at the high levels of dietary $\mathrm{CuSO}_{4}$.

It was decided to carry out a pair-feeding experiment in order to assess if the effects of adding dietary $\mathrm{CuSO}_{4}$ are due to direct toxicity or are indirect and caused by decreased food intake.

\section{EXPERIMENTAL}

Thirty-six, white 18-week-old hens (Shaver 288) were placed in galvanized iron cages each fitted with an individual feeder and nipple drinker. The temperature was maintained at $21 \pm 2^{\circ}$. The initial lighting, regimen of $11 \mathrm{~h}$ light and $13 \mathrm{~h}$ darkness was changed once per week until $17 \mathrm{~h}$ light and $7 \mathrm{~h}$ darkness was achieved. This latter lighting programme was maintained throughout the experiment. At 24 weeks, when all the hens had been laying for at least 2 weeks, they were randomly allocated to one of six treatment groups each containing six birds. The diets, fed ad lib. for 6 weeks, were a basal diet supplemented with $\mathrm{CuSO}_{4} \cdot 5 \mathrm{H}_{2} \mathrm{O}$ (treatments 2,4 and 6) at levels equivalent to 500,1000 and $2000 \mathrm{mg} \mathrm{Cu} / \mathrm{kg}$ and the same basal diet without added $\mathrm{CuSO}_{4}$ pair-fed to these treatments thus giving three control treatments (nos. 1, 3 and 5). The composition of the basal diet and fineness of grinding of the $\mathrm{CuSO}_{4} . \mathrm{s}_{2} \mathrm{O}$ have been given by Jackson (1977) and the control diet analyses reported by Stevenson \& Jackson (1980 $b$ ). 
The individual daily food intakes of hens on treatments 2,4 and 6 were measured and treatments 1, 3 and 5 pair-fed to these respective levels, the level of feeding being based on the previous day's mean food intake by the $\mathrm{CuSO}_{4}$-fed birds. Daily egg production, egg weight and initial and final body-weights were recorded. At the end of the 6-week feeding period all the hens were killed by decapitation. Blood was analysed for haemoglobin $(\mathrm{Hb})$ and packed cell volume (PCV) while $\mathrm{Cu}$ and aspartate aminotransferase (EC 2.6.1.1; AAT) levels were assayed in blood serum. The liver, kidneys, oviduct, ovary and gizzard were removed and weighed and $\mathrm{Cu}$, zinc and $\mathrm{Fe}$ concentrations in the liver and kidneys measured after drying at $100^{\circ}$. The lipid content of the liver was determined by the method of Folch et al. (1957).

Chemical and statistical analyses were as described by Stevenson \& Jackson (1980a).

\section{RESULTS}

Mean initial body-weight, body-weight change, food intake, egg number, mean egg weight, absolute tissue weights and these weights expressed as $\mathrm{g} / \mathrm{kg}$ body-weight are given in Table 1 together with liver lipid concentration. The attempt to equalize the food intake of each paired group was successful. Mean body-weight change and the liver, oviduct and ovary weights and these weights expressed as $\mathrm{g} / \mathrm{kg}$ body-weight were significantly decreased $(P<0.001)$ with decreasing levels of food intake but the presence of $\mathrm{CuSO}_{4}$ in the diets had no statistically significant effect for each pair-fed group. Mean egg number was significantly decreased with decreasing levels of food intake $(P<0.001)$. Over all, the presence of $\mathrm{CuSO}_{4}$ had no statistically significant effect on egg number but the presence of $\mathrm{CuSO}_{4}$ did depress mean egg number at all levels of addition and in particular at the 1000 $\mathrm{mg}$ added $\mathrm{Cu} / \mathrm{kg}$ diet at which level the effect was statistically significant. Mean egg weight was also significantly decreased $(P<0.05)$ with decreasing levels of food intake. Kidney weight and kidney weight per unit body-weight were significantly decreased with decreasing levels of food intake $(P<0.001)$ and increased by $\mathrm{CuSO}_{4}$ supplementation $(P<0.05)$. The level of food intake did not affect absolute gizzard weight but significantly increased this weight, when expressed as $\mathrm{g} / \mathrm{kg}$ body-weight $(P<0.001)$. Both absolute gizzard weight and gizzard weight expressed per unit body-weight were significantly increased by $\mathrm{CuSO}_{4}$ supplementation $(P<0.001)$ relative to the appropriate controls. Liver lipid concentration was significantly decreased with decreasing levels of food intake $(P<0.05)$ and although the absolute effect of $\mathrm{CuSO}_{4}$ addition was a decrease in liver lipid concentration this was not significantly different from the corresponding control at any of the three levels used.

The blood and blood serum results and the mean concentrations and total contents of $\mathrm{Cu}, \mathrm{Zn}$ and $\mathrm{Fe}$ in the liver and kidneys are presented in Table 2. Blood $\mathrm{Hb}, \mathrm{PCV}$ and AAT were significantly increased with decreasing levels of food intake $(P<0.01, P<0.05$ and $P<0.01$ respectively) although relative to the controls only AAT was significantly decreased $(P<0.001)$ by $\mathrm{CuSO}_{4}$ supplementation. Serum $\mathrm{Cu}$ levels were unaffected by any of the dietary treatments, the values being similar to those reported by Beck (1961) for whole blood $\mathrm{Cu}$.

Liver $\mathrm{Cu}$ concentration and total liver $\mathrm{Cu}$ content were significantly increased with decreasing levels of food intake and $\mathrm{CuSO}_{4}$ supplementation $(P<0.001)$. The food intake effect was not evident for treatments 1,3 and 5 and the effect of supplementation was restricted to treatments 2,4 and 6 . Liver $\mathrm{Zn}$ and $\mathrm{Fe}$ concentrations were significantly increased $(P<0.01$ and $P<0.001$ respectively), total liver $\mathrm{Zn}$ was significantly decreased and total liver $\mathrm{Fe}$ increased $(P<0.001)$ as the level of food intake decreased. Total liver $\mathrm{Zn}$ was significantly increased $(P<0 \cdot 05)$ by the presence of added dietary $\mathrm{CuSO}_{4}$. However, the mean total liver $\mathrm{Zn}$ values decreased as the $\mathrm{CuSO}_{4}$ intake increased. When the liver mineral results were expressed on a fat-free basis in general the trends observed were further accentuated and consequently these results are not presented. 
Effects of copper sulphate in the laying domestic fowl

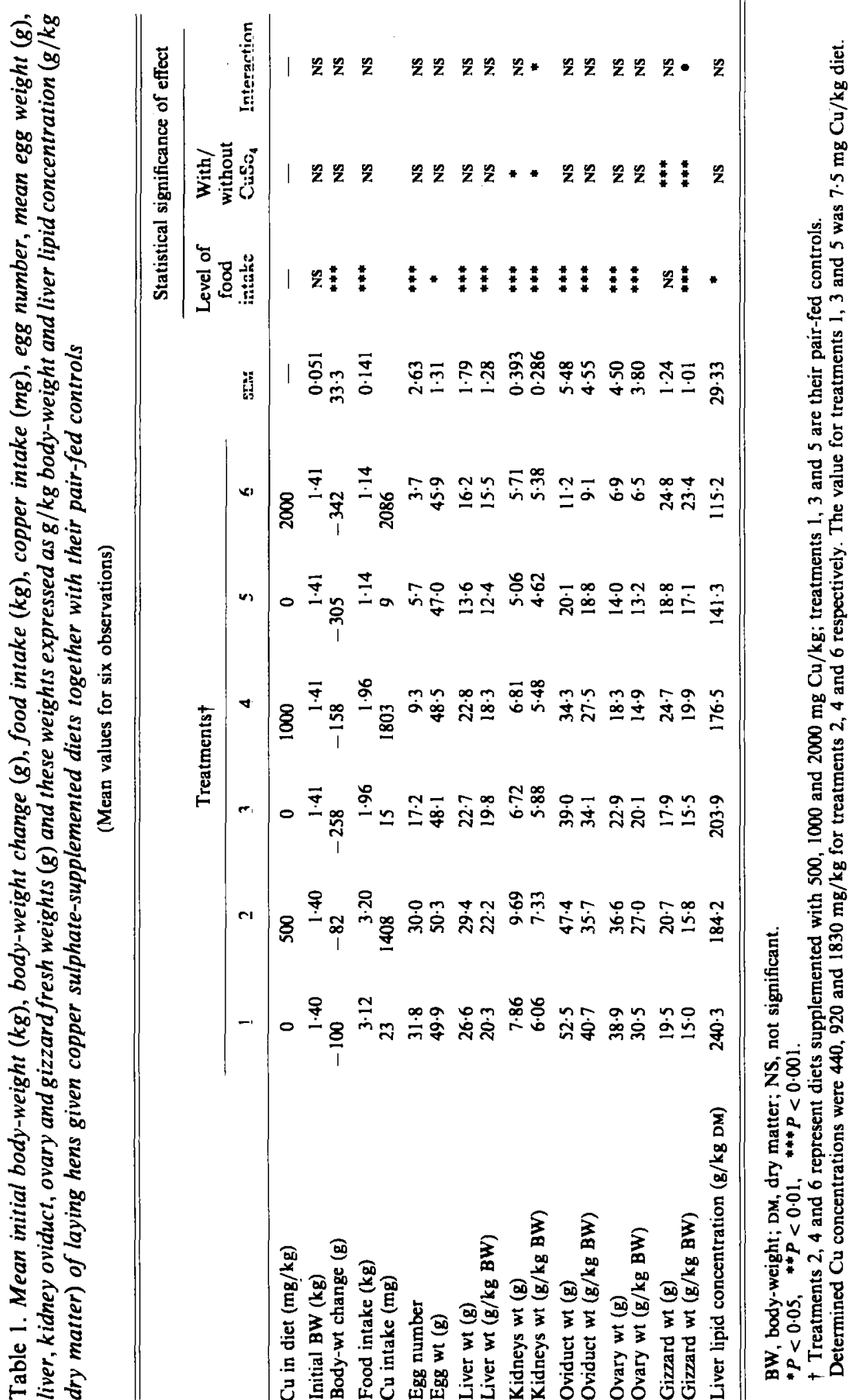




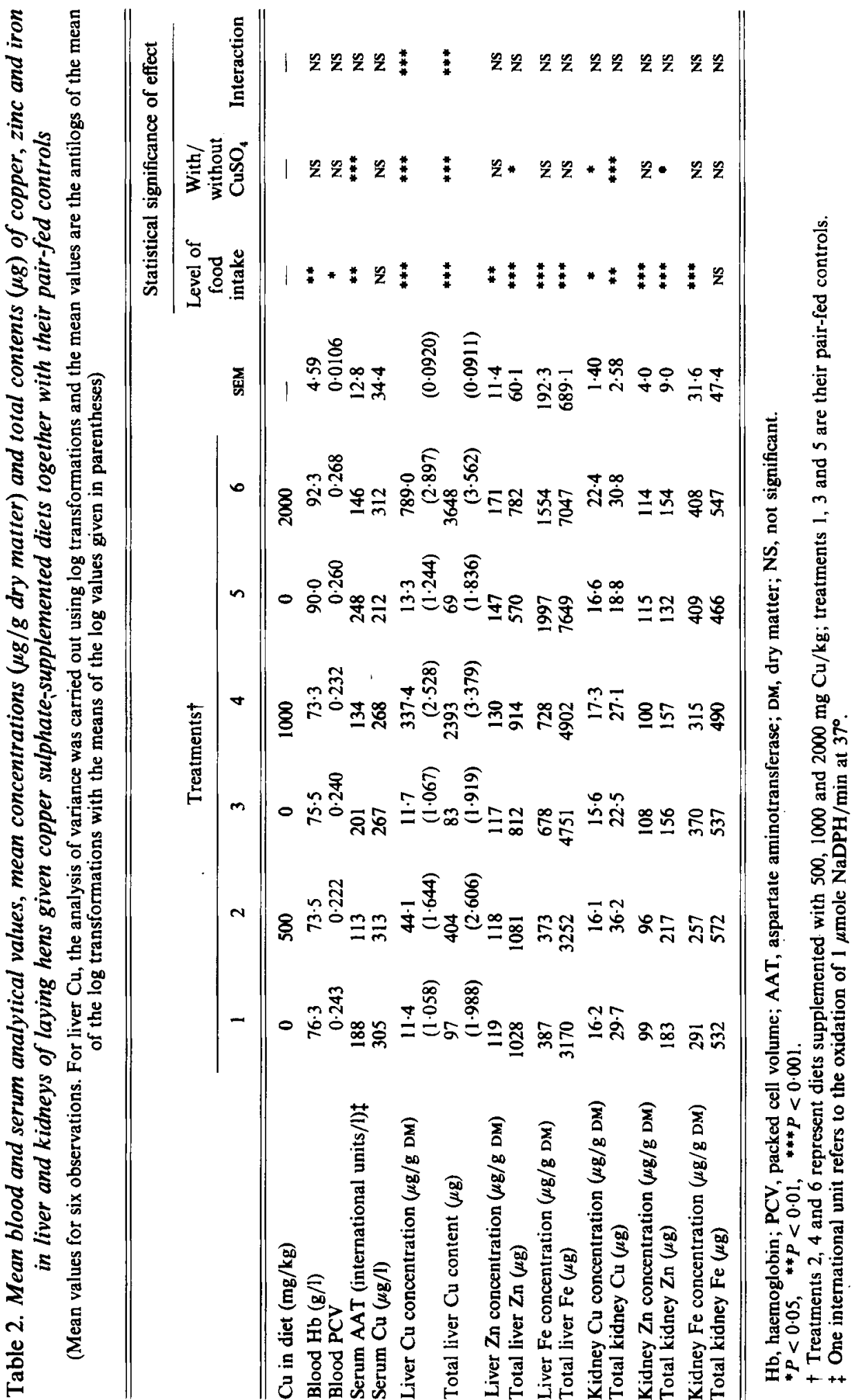


As the level of food intake decreased kidney $\mathrm{Cu}$ concentration $(P<0.05)$ and kidney $\mathrm{Zn}$ and $\mathrm{Fe}$ levels $(P<0.001)$ significantly increased but only the kidney $\mathrm{Cu}$ concentration was significantly increased $(P<0.05)$ by increasing dietary $\mathrm{CuSO}_{4}$ supplementation. Total kidney $\mathrm{Cu}$ and $\mathrm{Zn}$ were discreased with decreasing levels of food intake $(P<0.01$ and $P<0.001$ respectively) and both were increased, relative to the control diets, by $\mathrm{CuSO}_{4}$ supplementation ( $P<0.0 \mathrm{C} 1$ and $P<0.05$ respectively) although the levels tended to decrease with increasing dietary $\mathrm{CuSO}_{4}$ for treatments 2, 4 and 6. Total kidney $\mathrm{Fe}$ was unaffected by either the level of food intake or $\mathrm{CuSO}_{4}$ supplementation, the over-ail mean (+SEM) being $524 \pm 19 \cdot 5 \mu \mathrm{g}$.

\section{DISCUSSION}

The diets with the high levels of added dietary $\mathrm{CuSO}_{4}$ given to laying hens have produced the effects expected in the light of previous work from this Department. From the present experiment, it is apparent that many of the effects, including reduced body-weight gain, egg number, egg weight, liver, oviduct and ovary weights are mainly due to a reduction in food intake rather than to the presence of high levels of dietary added $\mathrm{CuSO}_{4}$. Fisher et al. (1971) using 5-week-old broiler chicks given diets containing $\mathrm{CuSO}_{4}$ equivalent to $750 \mathrm{mg} \mathrm{Cu} / \mathrm{kg}$ diet also found that the derreased body-weight gain could be attributed to the reduction in food intake rather than to the presence of the added $\mathrm{Cu}$ salt. However, comparison with their pair-feeding experiment is limited since it was of only 2 weeks duration.

It is not surprising that, in the present experiment, egg production was affected dramatically in both the $\mathrm{CuSO}_{4}$-fed hens and their pair-fed controls since the intakes of protein and energy, especially at the two highest levels of $\mathrm{CuSO}_{4}$ supplementation, were not sufficient to meet their dietary requirements as recommended by the Agricultural Research Council (1975).

Although the results now show that the depressing effect of dietary treatment on egg production can be mainly attributed to reduced food intake nevertheless the evidence also indicates an independent adverse affect of the dietary $\mathrm{CuSO}_{4}$ which attained statistical significance $(P<0.05)$ at the intermediate level of addition.

The depression of water intake at high $\mathrm{CuSO}_{4}$ intake levels (Jackson, 1977; Jackson et al. 1979) may be a factor adversely affecting egg production and could also contribute to the increase in blood $\mathrm{Hb}$ and PCV at the highest level of $\mathrm{CuSO}_{4}$ addition.

No obvious explanation can be given for the increase in serum AAT with decreasing food intake and the fact that the rean AAT value was, at each level of $\mathrm{CuSO}_{4}$ addition, depressed below the corresponding pair-fed control value does not suggest any tissue damage. In fact, such an effect, although rizported in other species, has not been demonstrated in the domestic fowl. In the light of the present results the apparent increase of serum AAT with increasing dietary $\mathrm{CuSO}_{4}$ rejorted by Jackson (1977) is now believed to be an effect of food intake.

The significant increase in gizzard weight $/ \mathrm{kg}$ body-weight has resulted from both the lower food intake and the inclusicin of $\mathrm{CuSO}_{4}$ at levels equivalent to 1000 and $2000 \mathrm{mg} \mathrm{Cu} / \mathrm{kg}$ diet. Similar effects of high dietary $\mathrm{CuSO}_{4}$ on gizzard weight in the laying hen have been reported by Jackson et al. (1979) and Stevenson \& Jackson $(1980 a, b)$. Pathological changes in gizzard integrity of broilers in response to dietary $\mathrm{CuSO}_{4}$ have been observed by Fisher et al. (1973) and Poupoulis \& Jensen (1976).

The increases in kidney weight per unit body-weight at the lowest and highest levels of $\mathrm{CuSO}_{4}$ supplementation were unexpected since decreases in kidney weight $/ \mathrm{kg}$ body-weight have been reported previously (Jackson, 1977; Jackson et al. 1979; Stevenson \& Jackson, $1980 a$ ).

Although the over-all effects of $\mathrm{CuSO}_{*}$ on oviduct and ovary weights were not significant, the results at 1000 and $2000 \mathrm{rag}$ added $\mathrm{Cu} / \mathrm{kg}$ indicate a depression of these due to the $\mathrm{CuSO}_{4}$ which is additional to that caused by restriction of intake. It is very possible that these effects 
would have been more definite if the experiment had been carried on for a longer period of time.

Although the statistical analyses attribute the reduction in liver lipid content to a decrease in the level of food intake the decrease in the mean value at each level of intake associated with the $\mathrm{CuSO}_{4}$ addition strongly suggests a depressing effect of the additive.

The increase of approximately $2000 \%$ in the liver $\mathrm{Cu}$ concentration at the highest level of $\mathrm{CuSO}_{4}$ addition substantiates the various results reported previously from this Department.

The slight but statistically significant increase in liver $\mathrm{Zn}$ per unit dry weight with reduced food intake appears to be a concentration effect resulting from reduced liver weight since the total $\mathrm{Zn}$ content decreased. An increase of liver $\mathrm{Zn}$ concentration in the presence of added dietary $\mathrm{CuSO}_{4}$ has been reported by Stevenson \& Jackson $(1980 \mathrm{~b})$. This increase of the liver $\mathrm{Zn}$ in the presence of added dietary $\mathrm{Cu}$ has also been noted in the pig by Ritchie et al. (1963) and Suttle \& Mills (1966) and does not necessarily indicate a lack of antagonism at the level of the intestine or other tissues since such an antagonist effect has been found by these authors.

The increases in liver Fe concentration and total liver Fe also agree with previous results (Jackson et al. 1979; Stevenson \& Jackson, 1980a,b) but the present results associate the differences with the reduction of food intake rather than with the dietary $\mathrm{CuSO}_{4}$. A number of factors may be involved in this effect including the reduced demand for Fe incorporation into the egg.

The increase in kidney $\mathrm{Cu}$ concentration with decreasing food intake is similar to the effect found by Stevenson \& Jackson $(1980 b)$ and is obviously attributable to the presence of the $\mathrm{CuSO}_{4}$ rather than level of food intake.

Stevenson \& Jackson (1980 b) suggested that an increase in kidney Fe concentration was related to increasing dietary $\mathrm{CuSO}_{4}$ but the present results indicate that this effect is an indirect one due to decreased food intake and not directly due to dietary $\mathrm{CuSO}_{4}$ concentration.

In this experiment the main effects directly attributable to the $\mathrm{CuSO}_{4}$ are the high liver $\mathrm{Cu}$, increased kidney $\mathrm{Cu}$ and kidney weight and increased gizzard weight. However, although the analyses presented attribute the depression of liver lipid and egg production to decreased food intake, it is apparent that the $\mathrm{CuSO}_{4}$ per se is also having a deleterious effect.

The authors thank Dr D. J. Kilpatrick for statistical analyses and Mrs R. Park, Mr W. Graham and Mr G. McC. Kirkpatrick for techical assistance.

\section{REFERENCES}

Agricultural Research Council (1975). The Nutrient Requirements of Farm Livestock no. 1, Poultry. London: H.M. Stationery Office.

Beck, A. B. (1961). Aust. J. agric. Res. 12, 743.

Fisher, C., Laursen-Jones, A. P., Hill, K. J. \& Hardy, W. S. (1973). Br. Poult. Sci. 14, 55.

Fisher, C., Wise, D. \& Filmer, D. G. (1971). 14th Wld's Poult. Congr. Madrid, p. 759.

Folch, J. Lees, J. \& Sloane Stanley, C. H. (1957). J. biol. Chem. 226, 497.

Griminger, P. (1977). Poult. Sci. 56, 359.

Jackson, N. (1977). Br. J. Nutr. 38, 93.

Jackson, N. \& Stevenson, M. H. (1981). Br. J. Nutr. 45, 99.

Jackson, N., Stevenson, M. H. \& Kirkpatrick, G. McC. (1979). Br. J. Nutr. 42, 253.

Poupoulis, C. \& Jensen, L. S. (1976). Poult. Sei. 55, 113.

Ritchie, H. D., Leucke, R. W., Baltzer, B. V., Miller, E. R., Ullrey, D. E. \& Hoefer, J. A. (1963). J. Nutr. $79,117$.

Stevenson, M. H. \& Jackson, N. (1980a). Br. J. Nutr. 43, 205.

Stevenson, M. H. \& Jackson, N. (1980b). Br. J. Nutr. 43, 551.

Suttle, N. F. \& Mills, C. F. (1966). Br. J. Nutr. 20, 135.

Thomas, M. C., Norvell, M. J., Calvert, C. C. \& Goatcher, W. D. (1974). Poult. Sci. 53, 1984, Abstr. 